\title{
Low expression of plakoglobin in intratumoral liver tissue is associated with poor survival after curative resection of Hepatocellular Carcinoma
}

\section{De-Ning Ma}

Zhejiang cancer hospital https://orcid.org/0000-0002-5560-8078

Zhuo Liu

Zhejiang cancer hospital

Jie Yuan

Department of Radiology, Shuguang Hospital Affiliated to Shanghai University of Traditional Chinese Medicine

Xin-Yi Gao

Department of Radiology, Zhejiang cancer hospital

\section{Dian-Dian Sun}

Zhejiang Chinese Medical University

Zhi-Xuan Fu ( $\nabla$ fuzx@zjcc.org.cn )

\section{Research}

Keywords: Plakoglobin, Hepatocellular carcinoma, Prognosis, Survival

Posted Date: February 14th, 2020

DOI: https://doi.org/10.21203/rs.2.23598/v1

License: (c) (1) This work is licensed under a Creative Commons Attribution 4.0 International License. Read Full License 


\section{Abstract}

Background: Plakoglobin also known as y-catenin, is a member of the Armadillo family. It's a structural and functional homologue of protein $\beta$-catenin with dual functions in cell-cell adhesion and cell signaling. However, the role of plakoglobin in hepatocellular carcinoma (HCC) is unclear to date. Our aim was to investigate the expression of plakoglobin in $\mathrm{HCC}$ and its correlation with prognosis and then to further study the underlying function.

Methods: Western Blot and qRT-PCR were used to examine the expression of plakoglobin in HCC cell lines and normal hepatocyte cell line. Immunohistochemical method was used to analyze the expression and relationship of plakoglobin in tissue microarray with $191 \mathrm{HCC}$ patients through Kaplan-Meier analysis.

Results: Patients with high expression of plakoglobin had a better survival compared with those with low expression (OS, $\mathrm{P}=0.002$; DFS, $\mathrm{P}=0.012$ ). Plakoglobin is an independent prognostic factor for patients $(\mathrm{OS}, \mathrm{P}=0.026$, $\mathrm{DFS}, \mathrm{P}=0.045)$. Plakoglobin was inversely consistent with the metastatic potential ability of HCC cell lines.

Conclusions: Our founding indicates plakoglobin is an independent prognostic marker of HCC, and patients with low expression of that had a poor survival. Plakoglobin may serve as a potential target for anti-HCC.

\section{Introduction}

Plakoglobin (also known as $\mathrm{\gamma}$-catenin), discovered more than 30 years ago as an adhesion protein associated with the cell membrane, is a member of the Armadillo family of proteins[1]. Plakoglobin is a structural and functional homologue of protein $\beta$-catenin, containing a central armadillo repeat domain[2]with dual functions in cell-cell adhesion and cell signaling[3, 4]. Both plakoglobin and $\beta$-catenin could interact with the cytoplasmic domain of cadherins, such as E-cadherin, tethering the cadherincatenin complex to the cytoskeleton, though plakoglobin was found to be only loosely associated with Ecadherin[3]. In addition, several evidences suggest that plakoglobin has signaling ability similar to $\beta$ catenin when it's not sequestered at the plasma membrane as a part of the desmosomes, plakoglobin is capable to participate in cell signaling $[5,6]$. However, unlike $\beta$-catenin that has a well-defined oncogenic potential as the terminal component involved in the Wnt signaling pathway [7, 8], plakoglobin is generally considered as a tumor or metastasis suppressor[9, 10], although its role in cancer is still controversial[3]. Recent some studies suggest that plakoglobin acts as a tumor-suppressor protein in some tumors, such as lung primary cancer, prostate cancer and esophageal cancer, its expression in these cancers is very low or completely absent $[11,12]$. Whereas other studies suggest that plakoglobin has a tumor-inducing effect or oncogenic activity[13-15]. It is possible that plakoglobin may have different roles in different malignancies. Recently, an immunohistochemical study revealed that $58 \%$ of human hepatocellular carcinoma (HCC) cases showed that reduced levels of E-cadherin associated with a declined expression of p120 catenin, $a-$ and $\beta$-catenin and plakoglobin in a comparable percentage of HCC patients[16]. 
Additionally, our previous study revealed that $\beta$-catenin could be activated by hypoxia in HCC and contributed to enhance the metastatic potential and poor prognosis[17]. In this situation, to investigate exact role of plakoglobin involved in HCC is an outstanding issue.

$\mathrm{HCC}$ is one of the most common type of primary tumors in the liver with increasing incidence. It is the second most common cause of cancer death in men and sixth-greatest cause of cancer death in women worldwide[18]. Only about $20 \%-30 \%$ of HCC patients are curable by surgical resection with a reported 5year $40 \%-50 \%$ survival rate and a high incidence of postoperative recurrence rate[ 19,20$]$, most patients diagnosed HCC are not candidate for curative treatments[21]. Postoperative recurrence may occur as a result of intrahepatic metastasis or de novo tumor occurrence[22]. Therefore, understanding the mechanism of tumor recurrence after curative resection is crucial for relieving this global health burden and improving the outcome of HCC patients. Metastasis and tumorigenesis is a multi-step process that the tumor cells acquire the ability to degrade the basement membrane and move from the primary site to distant sites forming the secondary tumors, which is the major cause of recurrence and cancer-related deaths. During this process, the intercellular adhesive complexes (mainly called adherens junctions and desmosomes) do limit the abnormal proliferation, migration and invasion and maintain the tissue integrity $[23,24]$. However, loss of the desmosomal adhesion is a precondition for the epithelialmesenchymal transition, indicated that the conversion of early stage primary tumors to invasive cancers.

In this study, to investigate the significance of plakoglobin in HCC patients' prognosis, we detected the expression of plakoglobin and analyzed the correlation between its expression and clinic pathological parameters in HCC patients. Moreover, we evaluated the expression of plakoglobin in several human HCC cell lines. Our results support the hypothesis that plakoglobin may act as a tumor suppressor in HCC.

\section{Materials And Method}

\section{Patients and specimens}

In our study, a total of $191 \mathrm{HCC}$ specimens were collected randomly from patients who underwent radical resection of pathologically confirmed tumors from 1999 to 2006 at the Liver Cancer Institute and Zhongshan Hospital (Fudan University, Shanghai, China). No patients received any preoperative anticancer treatment. The ethics committee of Zhongshan Hospital approved this research. All patients provided written informed consent to participate in this study.

\section{Tissue microarray (TMA) and Immunohistochemistry (IHC)}

A tissue microarray (TMA) was constructed as described previously[25]. Briefly, two cores were taken from each representative tumor tissue and from peritumoral liver tissue (in collaboration with Shanghai Biochip Company Ltd, Shanghai, China). Duplicate cylinders from two different areas, intratumoral and peritumoral (a total of four punches for each patient), were obtained. The rabbit anti-plakoglobin (Cat. No. A303-718A, CST) was used in the immunochemistry to investigate the expression. The density of positive staining was measured with the use of a computerized image system composed of a Leica CCD camera 
DFC420 connected to a Leica DM IRE2 microscope (Leica Microsystems Imaging Solutions Ltd, Cambridge, United Kingdom).

\section{Cell lines and Culture Conditions}

Four HCC cell lines (HepG2, HCCLM3, MHCC97L and MHCC97H) and human hepatic cell line L02 were used in cell experiments. HCCLM3, MHCC97L and MHCC97H are human HCC cell lines with high metastatic potential[26] (established at the liver cancer institute, Zhongshan Hospital, Fudan University, Shanghai, China) and HepG2 is HCC cell line with low metastatic potential (provided by the liver cancer institute, Zhongshan Hospital, Fudan University, Shanghai, China). L02 is normal liver cell line (obtained from the Cell Bank of the Chinese Academy of Sciences, Shanghai, China). Cells were incubated at $37^{\circ} \mathrm{C}$ in a humidified atmosphere of $5 \% \mathrm{CO}_{2}$ maintained in Dulbecco's modified Eagle's medium (DMEM; Invitrogen) containing 10\% fetal bovine serum (FBS; Invitrogen GIBCO), $100 \mathrm{U} \mathrm{ml}^{-1}$ penicillin and $50 \mu \mathrm{g} \mathrm{ml}$

1 streptomycin.

\section{RNA Isolation and qRT-PCR}

Total RNA was extracted from the four HCC cell lines (Hep G2, MHCC97L, MHCC97H and HCCLM3) and one normal liver cell line (L02) using Trizol reagent (Invitrogen) according to the manufacturer's instructions. qRT-PCR was performed using a ABI SYBR Green qPCR super Mix Kit according to the manufacturer's instructions. GAPDH was used as an internal control. The primers were as follows: plakoglobin forward primer 5'- ATGGAGGTGATGAACCTGATGGAG-3' and reverse primer 5'- TTGAGCGTGTACTGGCGCCC-3' and GAPDH forward primer 5' -TTCACCACCATGGAGAAGG -3' and reverse primer 5' -GGCATGGACTGTGGTCATGA-3'. Relative mRNA levels were calculated based on Ct values, corrected for GAPDH expression, according to the equation: $\mathrm{K} \times 2^{-\Delta \mathrm{Ct}}$ [ $\Delta \mathrm{Ct}=\mathrm{Ct}$ (plakoglobin)-Ct $(\mathrm{GAPDH})]$, while $\mathrm{K}$ is a constant. All the experiments were performed in triplicate.

\section{Western Blot}

Cells were lysed using cell lysis buffer (150 mM NaCl, 50 mM Tris-HCl, pH 8.0, 0.1\% SDS, 1\% Triton X-100) containing protease and phosphatase inhibitors. Equivalent amounts of whole cell extracts were subjected to SDS-PAGE gel and transferred to nitrocellulose membranes. The membranes were blocked with $5 \%$ non-fat milk for $2 \mathrm{~h}$ and then incubated with respective primary antibody overnight at $4^{\circ} \mathrm{C}$, followed by the incubation of the appropriate HRP-conjugated secondary antibody for $2 \mathrm{~h}$ at room temperature. Blots were visualized with an ECL detection kit (Pierce, IL) and analyzed using Quantity One 1-D Analysis Software (Bio-Rad, San Francisco, CA).

\section{Statistical analysis}

Data analysis was performed with SPSS 20.0 for Windows (SPSS Inc. Chicago, IL, USA). Unpaired Student's t-test or Pearson's $\chi^{2}$ test was used to compare quantitative variables. Kaplan-Meier analysis 
was used to determine the survival and recurrence, the Cox regression model was used to perform multivariate analysis. $P<0.05$ was considered statistically significant.

\section{Results}

\section{Patient characteristics and intratumoral plakoglobin expression}

We summarized the $191 \mathrm{HCC}$ patient (160 males, 31 females) characteristics in Table1. In this study, basic clinicopathological features, including age, gender, hepatitis B surface antigen (HBs-Ag), liver cirrhosis, a-fetoprotein, tumor size, tumor encapsulation, microvascular invasion, tumor differentiation and TNM stage were collected (Table1). According to the expression of plakoglobin in intratumoral tissues, these patients were classified into the high and low group, we investigated the relationship between plakoglobin expression and clinicopathological features. The results revealed that plakoglobin was statistically significant association with age, gender, HBs-Ag $(P=0.017)$, microvascular invasion $(P=0.014)$ and TNM stage $(P=0.040$ and $P=0.027)$. However, none of the other clinicopathological features such as alpha-fetoprotein (AFP), liver cirrhosis, tumor size, encapsulation or differentiation was correlated with plakoglobin expression in intratumoral tissues.

\section{Low expression in HCC patients showed poor prognosis}

We analyzed tissue from 191 patients with HCC using immunohistochemistry (IHC). Plakoglobin staining was mainly on the plasma membrane of tumor cells or hepatocytes (Figure $1 \mathrm{~A}$ ), the results revealed that patients with high expression of plakoglobin had a better overall survival (OS, $\mathrm{P}=0.002)$ and a better disease free survival (DFS, $P=0.012$ ) (Figure 1B). There were no statistically significant associations between the peritumoral plakoglobin expression and the OS $(P=0.145)$ and $D F S(P=0.377)$ rate after radical surgical resection of HCC (Figure $1 \mathrm{C}$ ). In addition to plakoglobin expression, univariate analysis revealed that AFP-1 $(P=0.033)$, tumor differentiation $(P=0.005)$, tumor size $(P<0.001)$ and microvascular invasion $(P<0.001)$ were associated with OS rate of patients with HCC. However, only the tumor size $(P=0.022)$ and microvascular invasion $(P=0.003)$ were associated the DFS of HCC patients (Table 2). Multivariate Cox's proportional Hazard model analysis suggested that high expression of plakoglobin as an independent prognostic factor for the OS $(P=0.026)$ and DFS $(P=0.045)$ rates of HCC patients (Table $3)$. Besides, microvascular invasion was also an independent prognostic factor for HCC. Moreover, we detected the expression of plakoglobin by western blot in four pairs tumor and matched peritumoral tissues randomly collected from four patients (Figure 1D). The results showed that the expression of plakoglobin was lower in tumor tissues than that in peritumoral tissues.

\section{Expression level of plakoglobin in HCC cell lines}

We detected the expression of plakoglobin mRNA by qPCR in four HCC cell lines (Figure 2A), and found that the expression level of plakoglobin mRNA was higher in L02 cell, and lower in HCC cell lines; moreover, the expression level of plakoglobin was inversely consistent with the metastatic potential ability of HCC cell lines. Furthermore, we detected the expression level of plakoglobin by western blot 
analysis in the above-mentioned five cell lines (Figure 2B), which showed that the result was consistent with that detected by qPCR.

\section{Discussion}

Plakoglobin was found more than thirty years ago as an adhesion protein associated with the cell membrane, it's a homologue of protein $\beta$-catenin. Although the role of $\beta$-catenin, an important component of the canonical Wnt signaling pathway, is well understood in various aspects of liver pathology, there is little information on the role of plakoglobin. The most documented role of plakoglobin within the cell is in cell-cell adhesion as a desmosomal protein. Recent emerged evidence has demonstrated that plakoglobin has novel roles in intracellular signaling and the regulation of gene expression. Similar to $\beta$-catenin, plakoglobin has two major roles in the cell: the mediation of cell-cell adhesion and cellular signaling, sometimes replace $\beta$-catenin for its function in the Wnt signaling pathway[27]. Despite some reports revealed that plakoglobin expression induced the mesenchymal-epithelial transition (MET) and suppressed tumorigenesis and metastasis, the underlying mechanisms that could account for its function activities had remained unclear, though the induction of MET by plakoglobin may occur via a common pathway involved $\beta$-catenin[28]. Some studies have suggested a tumor promoting activity of plakoglobin in malignancies; while others suggested it acted as a tumor suppressor, plakoglobin loss correlates with tumor progression, metastasis and poor prognosis. Loss of plakoglobin is thought to enhance the $\beta$-catenin signaling due to reduced competition for Lef/Tcf binding[29]. In breast cancer, Holen et al. found that plakoglobin acted as a tumor suppressor, loss of plakoglobin promoted the decreasing of cell-cell contact, and increased the invasive behavior of breast cancer cells in vivo [30]; however, the results of Aceto et al. suggested that plakoglobin acted as a metastasis promoter in breast cancer circulating tumor cells[14]. The role of plakoglobin in solid tumors existed controversy. While the role of plakoglobin in hepatocellular carcinoma had remained unclear.

In our study, we preliminary explored the expression of plakoglobin and its relationship with HCC. Our results revealed that HCC patients with high expression of plakoglobin had a better prognosis than those with low expression, and the expression of plakoglobin in peritumoral tissues showed no significance with the prognosis. To some extent, our results were consistent with some reported studies, suggesting that plakoglobin acted as a suppressor in hepatocellular carcinoma. Although the precise mechanisms of plakoglobin function on hepatocellular carcinoma development need to be further investigated, our study confirms the value of plakoglobin in the prediction of prognosis and the development of new therapeutic interventions.

\section{Conclusions}

In conclusion, our founding indicates plakoglobin is an independent prognostic marker of HCC, and patients with low expression of that had a poor survival. Plakoglobin may serve as a potential target for anti-HCC. 


\section{Abbreviations}

HCC, hepatocellular carcinoma; MET, mesenchymal-epithelial transition; TMA, tissue microarray; HBs-Ag, hepatitis B surface antigen

\section{Declarations}

\section{Ethics approval and consent to participate}

Zhongshan Hospital Research Ethics Committee approved the present study. Written informed consent for the use of their tissue and clinicopathological data was obtained from all patients.

\section{Consent for publication}

Not applicable.

\section{Availability of data and materials}

The datasets used and/or analyzed during the current study are available from the corresponding author on reasonable request.

\section{Competing interest}

The authors declare that they have no conflicts of interest.

\section{Funding}

This work was supported by the National Natural Science Foundation of China (Grant numbers:

No.81702371) and Natural Science Foundation of Zhejiang Province (Grant numbers: No.LY20H160004).

\section{Authors' contributions}

Author contribution as follows: De-Ning Ma and Zhi-Xuan Fu designed the experiments; De-Ning Ma and Zhuo Liu analyzed the clinicopathological data and performed the survival analysis. Jie Yuan, Xin-Yi Gao and Dian-Dian Sun performed the experiments and collected the follow-up information of patients; and De-Ning Ma wrote the paper. All authors read and approved the final manuscript.

\section{Acknowledgements}

Not applicable.

\section{References}

1. Hatzfeld M: The armadillo family of structural proteins. Int Rev Cyto/ 1999, 186:179-224. 
2. Rubinfeld B, Souza B, Albert I, Munemitsu S, Polakis P: The APC protein and E-cadherin form similar but independent complexes with alpha-catenin, beta-catenin, and plakoglobin. J Biol Chem 1995, 270:5549-5555.

3. Aktary Z, Pasdar M: Plakoglobin: role in tumorigenesis and metastasis. Int J Cell Biol 2012, 2012:189521.

4. Zhurinsky J, Shtutman M, Ben-Ze'ev A: Plakoglobin and beta-catenin: protein interactions, regulation and biological roles. J Cell Sci 2000, 113 (Pt 18):3127-3139.

5. Bradley RS, Cowin P, Brown AM: Expression of Wnt-1 in PC12 cells results in modulation of plakoglobin and E-cadherin and increased cellular adhesion. J Cell Biol 1993, 123:1857-1865.

6. Karnovsky A, Klymkowsky MW: Anterior axis duplication in Xenopus induced by the over-expression of the cadherin-binding protein plakoglobin. Proc Natl Acad Sci U S A 1995, 92:4522-4526.

7. Rao TP, Kuhl M: An updated overview on Wnt signaling pathways: a prelude for more. Circ Res 2010, 106:1798-1806.

8. Verkaar F, Zaman GJ: New avenues to target Wnt/beta-catenin signaling. Drug Discov Today 2011, 16:35-41.

9. Charpentier E, Lavker RM, Acquista E, Cowin P: Plakoglobin suppresses epithelial proliferation and hair growth in vivo. J Cell Bio/ 2000, 149:503-520.

10. Simcha I, Geiger B, Yehuda-Levenberg S, Salomon D, Ben-Ze'ev A: Suppression of tumorigenicity by plakoglobin: an augmenting effect of N-cadherin. J Cell Biol 1996, 133:199-209.

11. Shiina H, Breault JE, Basset WW, Enokida H, Urakami S, Li LC, Okino ST, Deguchi M, Kaneuchi M, Terashima $\mathrm{M}$, et al: Functional Loss of the gamma-catenin gene through epigenetic and genetic pathways in human prostate cancer. Cancer Res 2005, 65:2130-2138.

12. Fang WK, Liao LD, Gu W, Chen B, Wu ZY, Wu JY, Shen J, Xu LY, Li EM: Down-regulated gammacatenin expression is associated with tumor aggressiveness in esophageal cancer. World $\mathrm{J}$ Gastroenterol 2014, 20:5839-5848.

13. Hakimelahi S, Parker HR, Gilchrist AJ, Barry M, Li Z, Bleackley RC, Pasdar M: Plakoglobin regulates the expression of the anti-apoptotic protein BCL-2. J Biol Chem 2000, 275:10905-10911.

14. Aceto N, Bardia A, Miyamoto DT, Donaldson MC, Wittner BS, Spencer JA, Yu M, Pely A, Engstrom A, $\mathrm{Zhu} \mathrm{H}$, et al: Circulating tumor cell clusters are oligoclonal precursors of breast cancer metastasis. Cell 2014, 158:1110-1122.

15. Fang J, Xiao L, Zhang Q, Peng Y, Wang Z, Liu Y: Junction plakoglobin, a potential prognostic marker of oral squamous cell carcinoma, promotes proliferation, migration and invasion. J Oral Pathol Med 2019.

16. Zhai B, Yan HX, Liu SQ, Chen L, Wu MC, Wang HY: Reduced expression of E-cadherin/catenin complex in hepatocellular carcinomas. World J Gastroenterol 2008, 14:5665-5673.

17. Liu L, Zhu XD, Wang WQ, Shen Y, Qin Y, Ren ZG, Sun HC, Tang ZY: Activation of beta-catenin by hypoxia in hepatocellular carcinoma contributes to enhanced metastatic potential and poor 
prognosis. Clin Cancer Res 2010, 16:2740-2750.

18. Torre LA, Bray F, Siegel RL, Ferlay J, Lortet-Tieulent J, Jemal A: Global cancer statistics, 2012. CA Cancer J Clin 2015, 65:87-108.

19. Zhou XD, Tang ZY, Yang BH, Lin ZY, Ma ZC, Ye SL, Wu ZQ, Fan J, ., Qin LX, Zheng BH, \%J Cancer: Experience of 1000 patients who underwent hepatectomy for small hepatocellular carcinoma. 2001, 91:1479-1486.

20. Waly Raphael S, Yangde Z, Yuxiang C: Hepatocellular carcinoma: focus on different aspects of management. ISRN Oncol 2012, 2012:421673.

21. Poon D, Anderson BO, Chen LT, Tanaka K, Lau WY, Van Cutsem E, Singh H, Chow WC, Ooi LL, Chow P, et al: Management of hepatocellular carcinoma in Asia: consensus statement from the Asian Oncology Summit 2009. Lancet Oncol 2009, 10:1111-1118.

22. Tung-Ping Poon R, Fan ST, Wong J: Risk factors, prevention, and management of postoperative recurrence after resection of hepatocellular carcinoma. Ann Surg 2000, 232:10-24.

23. Holthofer B, Windoffer R, Troyanovsky S, Leube RE: Structure and function of desmosomes. Int Rev Cytol 2007, 264:65-163.

24. Garrod D, Chidgey M: Desmosome structure, composition and function. Biochim Biophys Acta 2008, 1778:572-587.

25. Gao Q, Qiu SJ, Fan J, Zhou J, Wang XY, Xiao YS, Xu Y, Li YW, Tang ZY: Intratumoral balance of regulatory and cytotoxic $T$ cells is associated with prognosis of hepatocellular carcinoma after resection. J Clin Oncol 2007, 25:2586-2593.

26. Li Y, Tang ZY, Ye SL, Liu YK, Chen J, Xue Q, Chen J, Gao DM, Bao WH: Establishment of cell clones with different metastatic potential from the metastatic hepatocellular carcinoma cell line MHCC97. World J Gastroenterol 2001, 7:630-636.

27. Zhurinsky J, Shtutman M, Ben-Ze'ev A: Differential mechanisms of LEF/TCF family-dependent transcriptional activation by beta-catenin and plakoglobin. Mol Cell Biol 2000, 20:4238-4252.

28. Li Z, Gallin WJ, Lauzon G, Pasdar M: L-CAM expression induces fibroblastepidermoid transition in squamous carcinoma cells and down-regulates the endogenous N-cadherin. J Cell Sci 1998, 111 ( Pt 7):1005-1019.

29. Maeda O, Usami N, Kondo M, Takahashi M, Goto H, Shimokata K, Kusugami K, Sekido Y: Plakoglobin (gamma-catenin) has TCF/LEF family-dependent transcriptional activity in beta-catenin-deficient cell line. Oncogene 2004, 23:964-972.

30. Holen I, Whitworth J, Nutter F, Evans A, Brown HK, Lefley DV, Barbaric I, Jones M, Ottewell PD: Loss of plakoglobin promotes decreased cell-cell contact, increased invasion, and breast cancer cell dissemination in vivo. Breast Cancer Res 2012, 14:R86.

\section{Tables}

Table 1. Intratumoral plakoglobin expression and clinicopathological features 


\begin{tabular}{|c|c|c|c|}
\hline \multirow[t]{3}{*}{ Variables } & \multicolumn{3}{|c|}{ Intratumoral plakoglobin expression $(\mathrm{n}=191)$} \\
\hline & Low $(n=91)$ & High $(n=100)$ & $P$ value \\
\hline & \multicolumn{3}{|c|}{$\overline{\text { No. of patients } 47.64 \% \text { No. of patients } 52.36 \%}$} \\
\hline Age, years† & $50.24 \pm 11.271$ & $54.77 \pm 10.846$ & 0.005 \\
\hline Gender & & & 0.040 \\
\hline Male & 71 & 89 & \\
\hline Female & 20 & 11 & \\
\hline HBs-Ag & & & $0.017^{*}$ \\
\hline Positive & 83 & 78 & \\
\hline Negative & 8 & 21 & \\
\hline AFP-1 & & & 0.521 \\
\hline$\leq 200 \mathrm{ng} / \mathrm{mL}$ & 44 & 53 & \\
\hline$>200 \mathrm{ng} / \mathrm{mL}$ & 47 & 47 & \\
\hline AFP-2 & & & 0.207 \\
\hline$\leq 20 \mathrm{ng} / \mathrm{mL}$ & 25 & 36 & \\
\hline$>20 \mathrm{ng} / \mathrm{mL}$ & 66 & 64 & \\
\hline Liver cirrhosis & & & 0.713 \\
\hline Yes & 23 & 23 & \\
\hline No & 68 & 77 & \\
\hline Tumor size, cm $\dagger$ & $5.919 \pm 4.127$ & $5.110 \pm 3.362$ & 0.138 \\
\hline Tumor encapsulation & & & $0.875^{*}$ \\
\hline Complete & 44 & 49 & \\
\hline None & 47 & 50 & \\
\hline Microvascular invasion & & & 0.014 \\
\hline Yes & 47 & 34 & \\
\hline No & 44 & 66 & \\
\hline Tumor differentiation & & & 0.922 \\
\hline I-II & 67 & 73 & \\
\hline III-IV & 24 & 27 & \\
\hline TNM stage- & & & 0.040 \\
\hline I & 11 & 10 & \\
\hline II & 30 & 51 & \\
\hline IIIA & 50 & 39 & \\
\hline TNM stage & & & 0.027 \\
\hline I-II & 41 & 61 & \\
\hline III-IV & 50 & 39 & \\
\hline
\end{tabular}

†Student's t-test. AFP: a-fetoprotein; HBs-Ag: Hepatitis B virus surface antigen; TNM: tumor-node-metastais.

*Missing data.

Table 2. Univariate analyses of factors associated with survival and recurrence

\begin{tabular}{|c|c|c|}
\hline Factors & OS, $P$ value & DFS, $P$ value \\
\hline Age: $<55$ vs $\geq 55$ years & 0.849 & 0.677 \\
\hline Gender: female vs male & 0.343 & 0.588 \\
\hline HBs-Ag & 0.393 & 0.705 \\
\hline Liver cirrhosis: yes vs no & 0.303 & 0.744 \\
\hline AFP-1: >200ng/mL vs $\leq 200 \mathrm{ng} / \mathrm{mL}$ & 0.033 & 0.106 \\
\hline AFP-2: >20ng/mL vs $\leq 20 \mathrm{ng} / \mathrm{mL}$ & 0.104 & 0.132 \\
\hline Tumor differentiation: III-IV vs I-II & 0.005 & 0.122 \\
\hline Tumor size: $>5 \mathrm{~cm}$ vs $\leq 5 \mathrm{~cm}$ & 0.000 & 0.022 \\
\hline Tumor encapsulation: complete vs none & 0.795 & 0.870 \\
\hline Microvascular invasion: yes vs no & 0.000 & 0.003 \\
\hline Intratumoral plakoglobin high vs low & 0.002 & 0.012 \\
\hline
\end{tabular}


Abbreviations: AFP: a-fetoprotein; OS, overall survival; DFS, disease-free survival.

Table 3. Multivariate analyses of factors associated with survival and recurrence

\begin{tabular}{|c|c|c|c|c|c|c|c|c|}
\hline \multirow[b]{3}{*}{ Factors } & \multicolumn{4}{|c|}{ OS } & \multicolumn{4}{|c|}{ DFS } \\
\hline & \multirow[b]{2}{*}{ Univariate } & \multicolumn{3}{|c|}{ Multivariate } & \multirow[b]{2}{*}{ Univariate $P$} & \multicolumn{3}{|c|}{ Multivariate } \\
\hline & & Hazard & o 95\% CI & $P$ & & Hazard Ratio & $95 \%$ CI & $P$ \\
\hline AFP-1: >200ng/mL vs $\leq 200 \mathrm{ng} / \mathrm{mL}$ & 0.033 & & & NA & 0.106 & & & NA \\
\hline Tumor differentiation: III-IV vs I-II & 0.005 & & & NA & 0.122 & & & NA \\
\hline Tumor size: $>5 \mathrm{~cm}$ vs $\leq 5 \mathrm{~cm}$ & 0.000 & 0.378 & $0.221-0.6$ & 180.000 & 0.022 & 0.663 & $0.421-1.044$ & 0.076 \\
\hline Microvascular invasion: yes vs no & 0.000 & 0.342 & $0.202-0.5$ & 300.000 & 0.003 & 0.590 & $0.373-0.934$ & 0.024 \\
\hline Intratumoral plakoglobin high vs low & 0.002 & 0.577 & $0.342-0.9$ & 740.026 & 0.012 & 1.597 & $1.011-2.523$ & 0.045 \\
\hline
\end{tabular}

Abbreviation: AFP: a-fetoprotein. NA: not adopted.

\section{Figures}


A

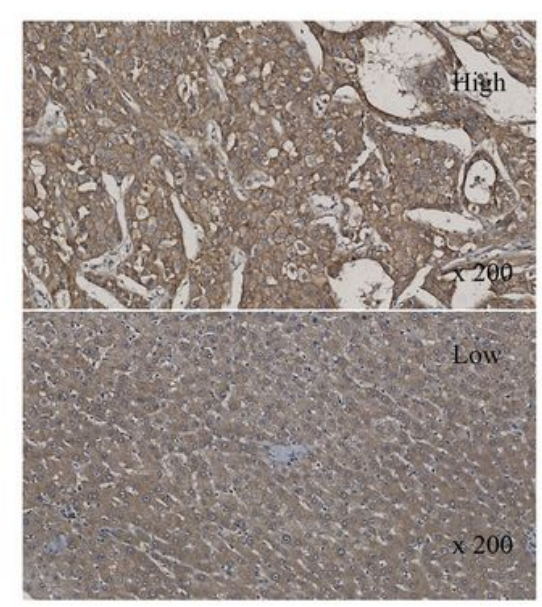

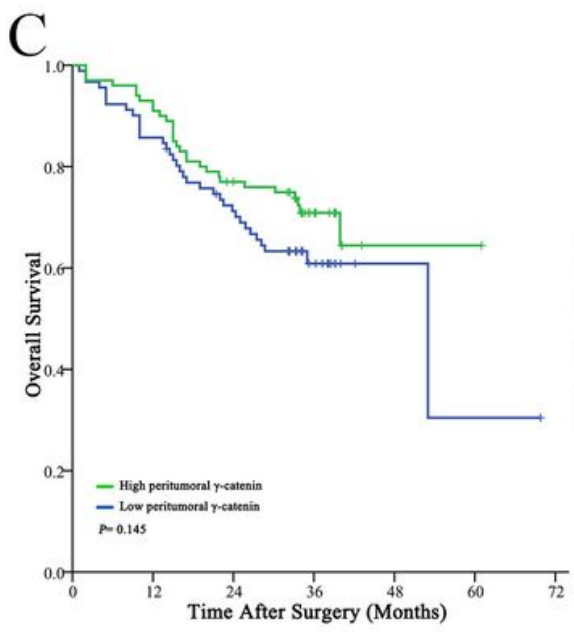

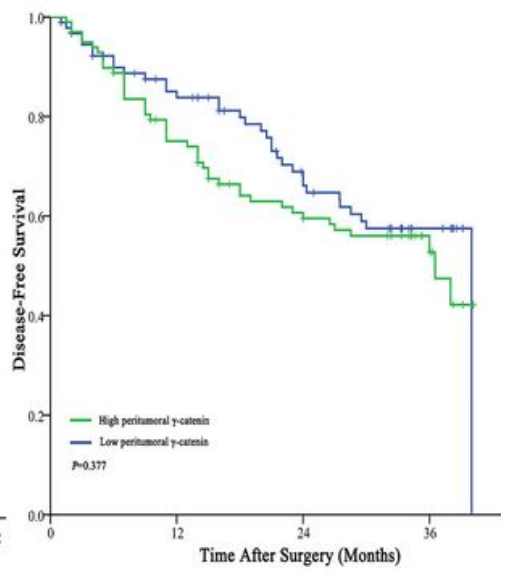

B

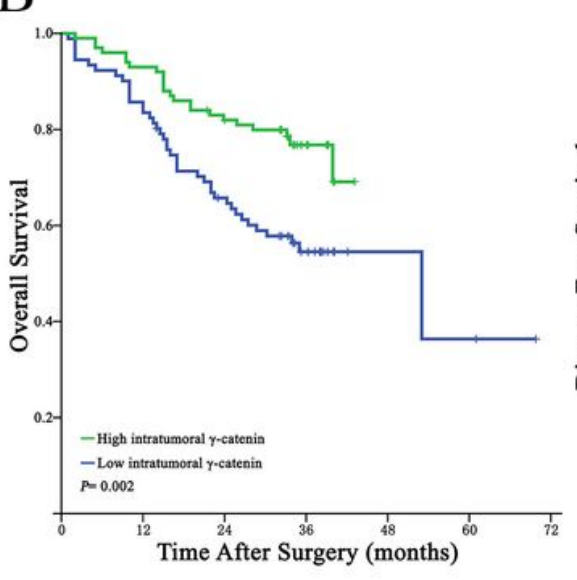

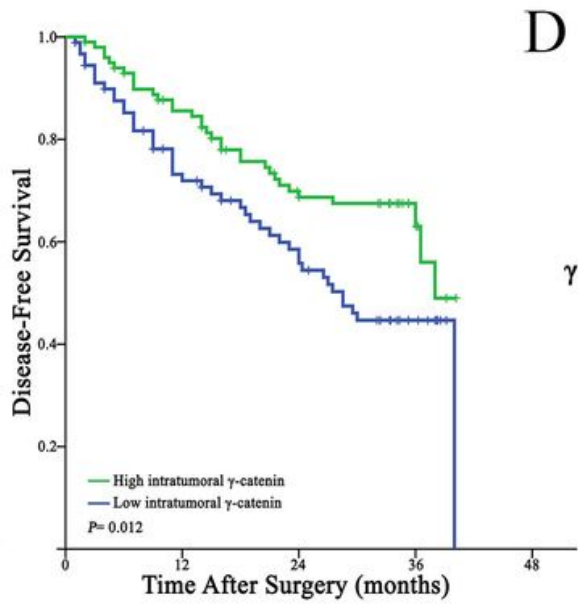

$\mathrm{D}$

\section{Figure 1}

$1 \mathrm{~A}$, Immunohistochemistry staining (magnification, X200), demonstrated the expression of plakoglobin in HCC tissues. B, Overall survival and Disease-free survival according to the intratumoral expression of plakoglobin. C, Overall survival and Disease-free survival according to the peritumoral expression of plakoglobin. D, Western blot assay showed the expression of plakoglobin in four paired fresh tissues (tumor tissue and peritumoral tissue)

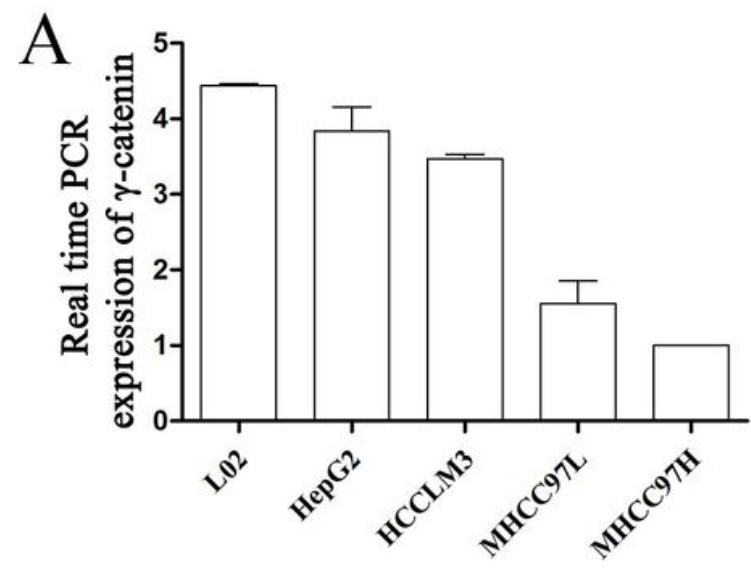

B

$\gamma$-catenin $\beta$-actin 
Figure 2

A, qRT-PCR assay showed the expression of plakoglobin in liver cancer cells and normal liver cell. B, Western blot assay verified the expression of plakoglobin in the above-mentioned cells. 